\title{
EVALUATION OF HARDNESS AND DUCTILITY OF AA 2014/B4C/ SHORT E-GLASS AS HYBRID COMPOSITES AND STUDIES ON THE EFFECT OF PROCESS PARAMETER USING TAGUCHI ANALYSIS
}

\author{
Srinivas $\mathbf{R}^{1}$, Mohan $\mathrm{Nc}^{2}$, Manjula ${ }^{3}$, Lingaraju ${ }^{4}$ \\ srinivasr038@gmail.com.
}

\begin{abstract}
The present study was aimed at evaluating the hardness and ductility of boron carbide and short E-glass of AA 2014 composites. These AMCs with individual and multiple reinforcement (hybrideMMCs) are finding increased applications in aerospacertechnology, automobileg, space, underwater and transportationiapplications. An effort is made to enhance hardness \& ductility of AMCs by reinforcing AA 2024 matrix with varying proportion of both B4C and Short E-glass fiber by stir casting method. Aluminum alloy matrix varying proportions of boron carbide particulates and Short E-glass fibers were fabricated. The hardness and ductility of the fabricated AMCs were analyzed. After obtaining results the taguchi analysis (MINITAB17) is done for input response such as composition, stirring speed and, stirring temperature by selecting the L16 orthogonal array to study the effect of each process parameter for hybrid composite material. Based on the results obtained from hardness test of the metal matrix composites it is observed that, the hardness increases as the increase in the amount both B4C of short E-glass but ductility of hybrid composite material decreases.
\end{abstract}

Key Words: AA2014, boron carbide, E-glass fiber, orthogonal array, signal-to-noise ratio, MINITAB17 ****

\section{INTRODUCTION}

The volume fractionof reinforcement in the microstructure as low as $5 \%$ and as high as $20 \%$ plays a Major role in the powder consolidated Al-B4C MMCs. The density of the every sample reduces in a small variation with respect to the increment percentage of reinforcement due to the low density value of reinforcement. The hardness values were gradually increasing according to the percentage of increment in the reinforcement. The hardness value is very high for the $20 \%$ reinforced B4C sample [6].

\section{FABRICATION OFCOMPOSITES}

The fabrication of AA-2014, B4C and Short E-glass fiber composites were carried out by stir casting process. The diagram of the experimental set up used for making these composites is shown in figure-1. Boron carbide particles and short E-glass fiber were preheated at around $800^{\circ} \mathrm{C}$ for 1 hrs.Tomaketheir surfaces oxidized. Al -2014 alloy ingots were taken into a graphite crucible and melted in an electrical furnace. The preheated boron carbide $(2 \%, 4 \%$, $6 \%, 8 \%$ ) particulates and varying proportion of Short Eglass fiber $(2 \%, 4 \%, 6 \%, 8 \%)$ were added and mixed with mechanical stirring at 300rpm for $5 \mathrm{~min}$. The final temperature was controlled to be around $750{ }^{0} \mathrm{C}$. After stirring the melt was poured into cast steel moulds of $14 \mathrm{~mm}$ diameter dies and allowed to cool to obtain cast rods. The samples were prepared from these cast rods.

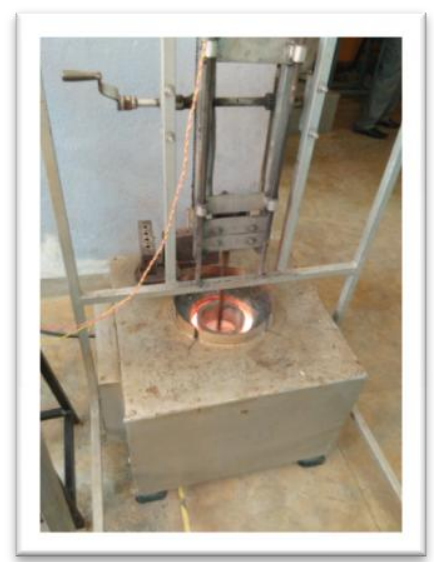

Figure1: Stir Casting Process

\section{EXPERIMENTAL PROCEDURE}

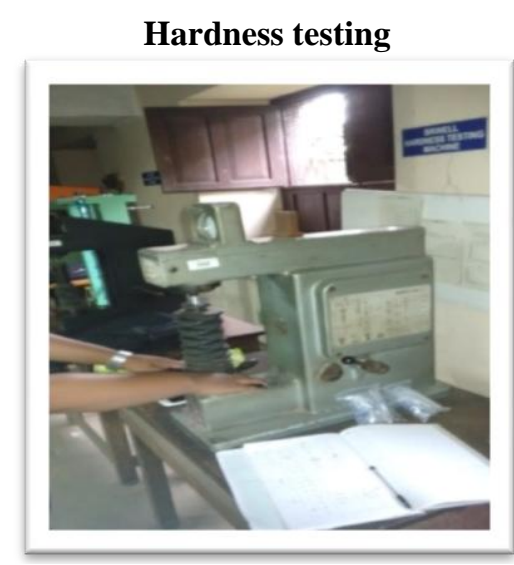

Figure2: Hardness test 
Hardness is a property of a material to resist permanent deformation. The hardness of a material may be determined by conducting scratch test or surface indentation methods. The scratch test is normally used to determine the hardness of ceramics materials. The indentation test involves producing permanent deformation by pressing indentor of material in to the surface.

\section{Design of Experiment using Taguchi analysis}

This work contains the detailed procedure of taguchi analysis. The primary goals of design of experiment are to:

- Determine the variables (factors) and their magnitude that influence response.

- Determine the levels for those variables (factors).

- Determine how to manipulate these variables (factors) to control the response

\section{RESULTS AND DISCUSSIONS}

\section{Hardness:}

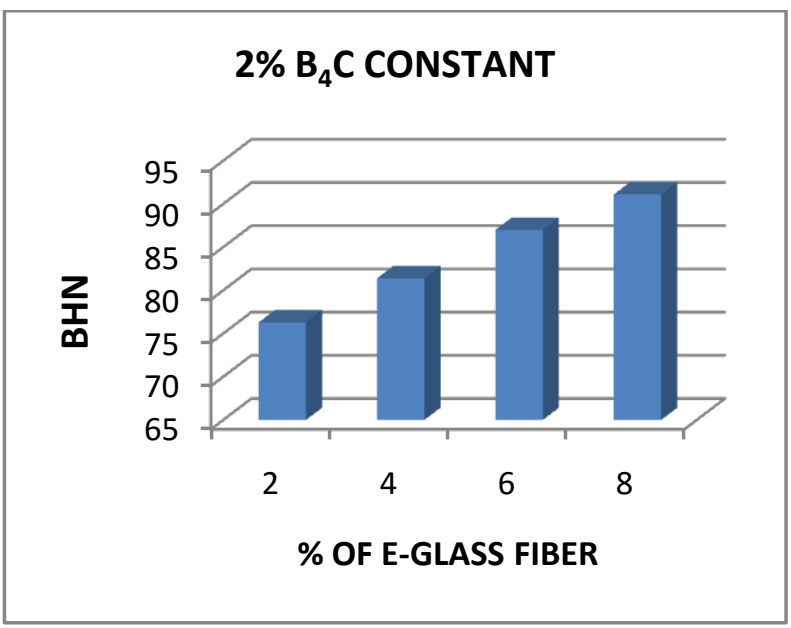

Figure3: Hardness v/s varying $\%$ of short E-glass fiber (2\% B4C constant)

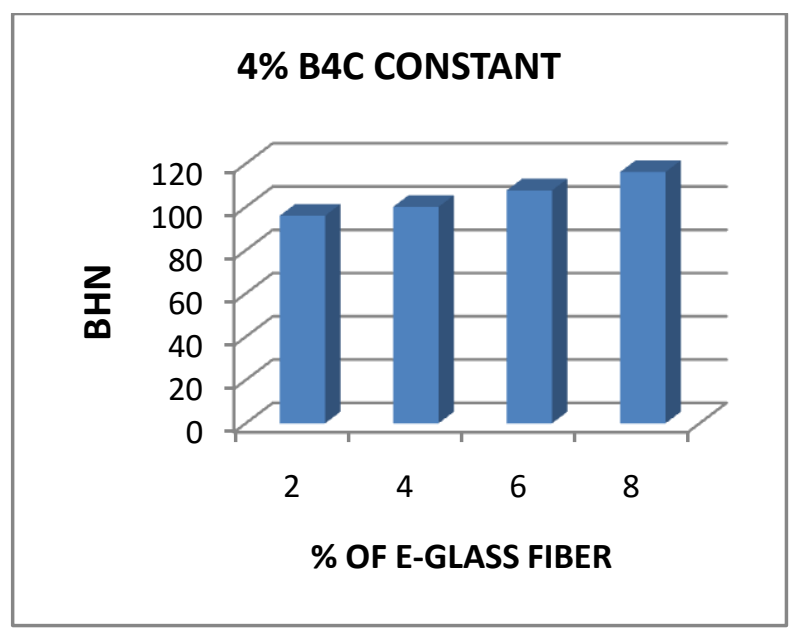

Figure4: Hardness v/s varying \% of short E-glass fiber (4\% B4C constant)

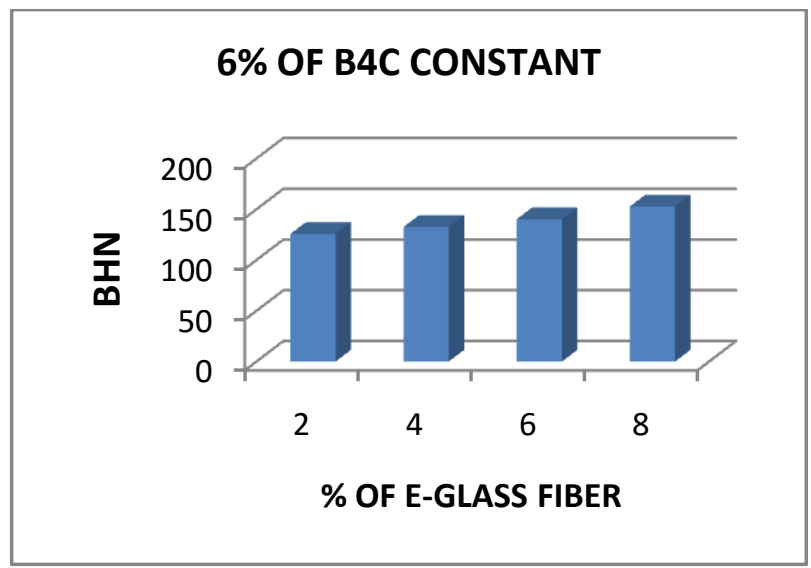

Figure5: Hardness v/s varying $\%$ of short E-glass fiber $(6 \%$ B4C constant)

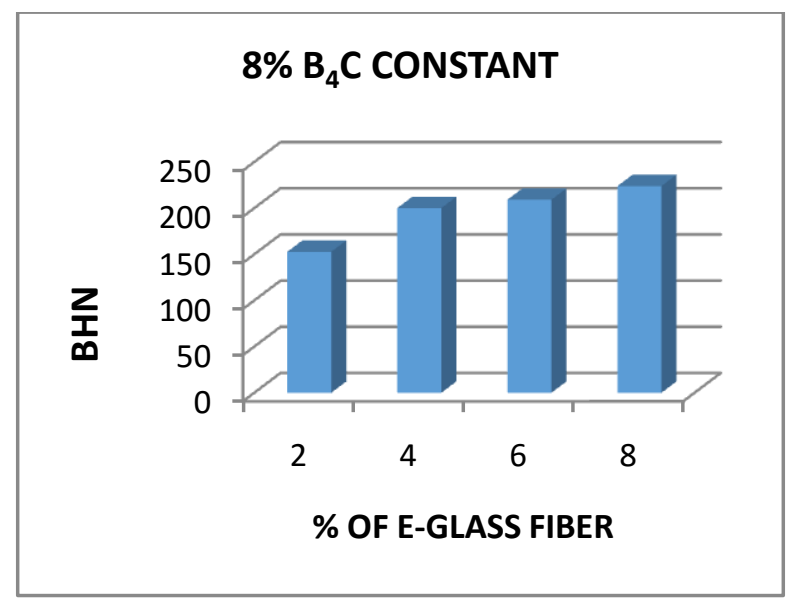

Figure 6: Hardness v/s varying \% of short E-glass fiber $(8 \%$ B4C constant)

The tests revealed that,the hardness test is carried in Brinell hardness machine. The figure 3, 4, 5, 6 shows the hardness for each composition of the specimens, if the percentage of boron carbide increases with increasing the short E-glass fiber thus hardness (BHN) also gradually increases. The specimens having highest BHN exhibits better hardness.

Ductility:

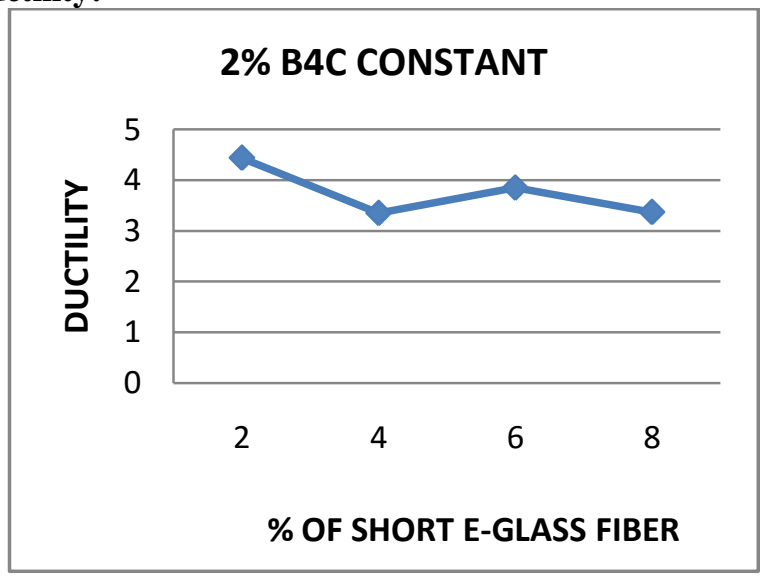

Figure 7: Ductility v/s varying \% of short E-glass fiber $(2 \%$ B4C constant) 


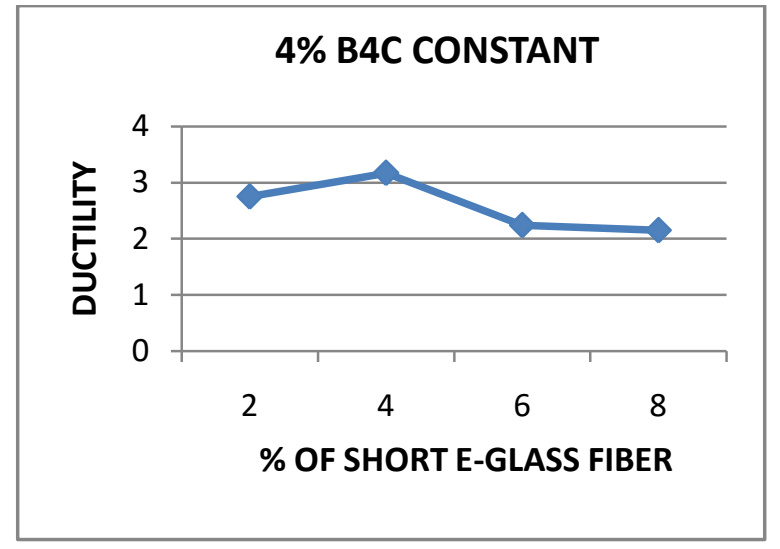

Figure 8:Ductility v/s varying \% of short E-glass fiber (4\% B4C constant)

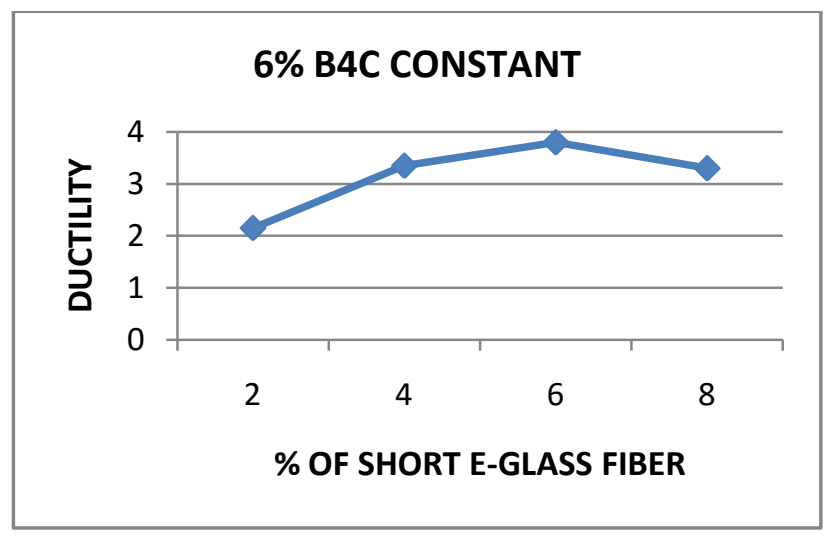

Figure 9:Ductility v/s varying \% of short E-glass fiber (6\% B4C constant)

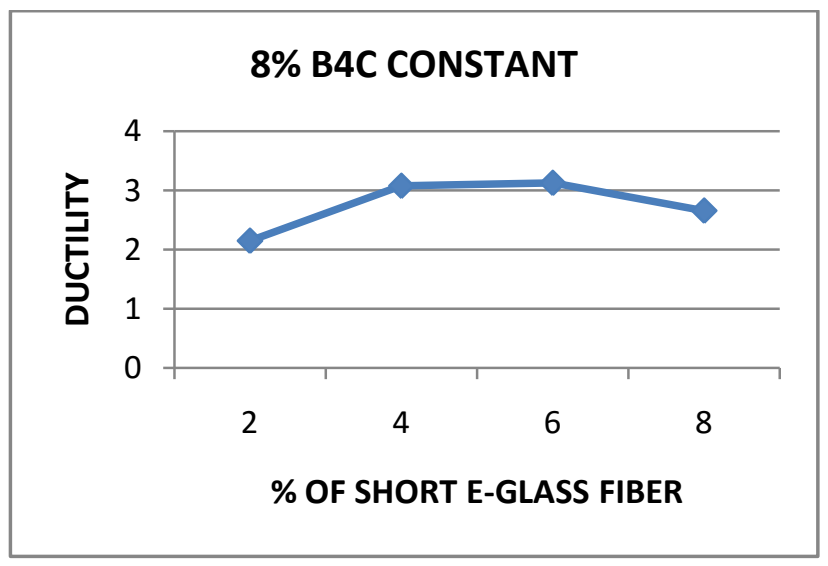

Figure 10:Ductility v/s varying $\%$ of short E-glass fiber $(8 \%$ B4C constant)

From the figure $7,8,9,10$ it is seen that the as the reinforcement increases there is decreases in the ductility $4.44 \%$ to $2.66 \%$.

\section{Design of Experiment:}

Effect of each parameter on hardness of hybrid composites:
Table 1: Mean $\mathrm{S} / \mathrm{N}$ ratios for Hardness

\begin{tabular}{|l|l|l|l|l|}
\hline LEVELS & 1 & 2 & 3 & 4 \\
\hline $\mathrm{A}$ & 40.74 & 41.67 & 42.19 & 42.79 \\
\hline $\mathrm{B}$ & 38.46 & 40.40 & 42.76 & 45.78 \\
\hline $\mathrm{C}$ & 38.46 & 40.40 & 42.76 & 45.78 \\
\hline
\end{tabular}

The table 1 mean shows $\mathrm{S} / \mathrm{N}$ ratio for hardness of the hybrid composite from figure 11 mean $\mathrm{S} / \mathrm{N}$ ratio it has clearly indicated the effect on hardness.

\section{Effect of \% of composition:}

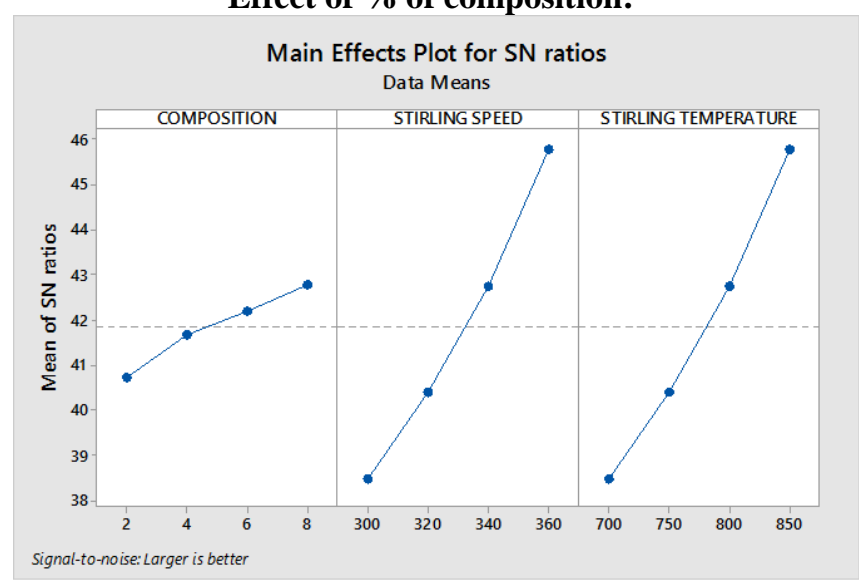

Figure 11: Main effects plot for $\mathrm{S} / \mathrm{N}$ ratios on hardness

Figure 11 clearly shows that if \% of composition increases, the hardness of hybrid composite increases. If composition is the main parameter that affects the hardness of hybrid composite from table 1 weight $\%$ of composition increases, the mean $\mathrm{S} / \mathrm{N}$ ration for the hardness increases showed the values 40.74 to 42.79 , which are achieved at constant $8 \%$ boron carbide is reinforced with AA2014.

\section{Effect of stirring speed}

From the figure 11 is clearly seen that if stirring speed increase from $300 \mathrm{rpm}$ to $360 \mathrm{rpm}$, the hardness of the composite increase to $76.3 \mathrm{BHN}$ to $223.9 \mathrm{BHN}$. From table 1 shows the mean $\mathrm{S} / \mathrm{N}$ ratio for hardness of the composite is increases from 40.40 to 41.67 are achieved at $360 \mathrm{rpm}$ speed.

\section{Effect of stirring temperature}

From the figure11 if hardness of the hybrid composite increased as the stirring temperature increased from $700^{\circ} \mathrm{Cto}$ $850^{\circ} \mathrm{C}$. The mean $\mathrm{S} / \mathrm{N}$ ratio for hardness of material is increases from 40.40 to 41.67 which are achieved at $850^{\circ} \mathrm{C}$ stirring temperature.

Effect of each parameter on the ductility

Table 2: Mean $\mathrm{S} / \mathrm{N}$ ratio for ductility

\begin{tabular}{|l|c|c|l|l|}
\hline LEVELS & \multicolumn{1}{|l|}{1} & 2 & 3 & 4 \\
\hline $\mathrm{A}$ & 9.721 & 10.472 & 9.749 & 9.017 \\
\hline $\mathrm{B}$ & 11.428 & 8.115 & 10.709 & 8.707 \\
\hline $\mathrm{C}$ & 11.428 & 8.115 & 10.709 & 8.707 \\
\hline
\end{tabular}


The table 2 shows mean $\mathrm{S} / \mathrm{N}$ ratio for hardness of the hybrid composite.Picture 12 shows mean $\mathrm{S} / \mathrm{N}$ ratio and it is clearly indicated the different effects on hardness.

\section{Effect of \% of composition}

Figure 12 clearly shows the that $\%$ of composition increases, thus ductility of hybrid composite increases from 9.721 to 10.472 up to level 2 after that the ductility decreases from 10.472 to 9.017 .

\section{Effect of stirring speed}

If the stirring speed increases from $300 \mathrm{rpm}$ to $320 \mathrm{rpm}$, thus the mean $\mathrm{S} / \mathrm{N}$ ratio decreases from 11.428 to 8.115 up to level 2. Again the stirring speed increases from $340 \mathrm{rpm}$ to $360 \mathrm{rpm}$ thus $\mathrm{S} / \mathrm{N}$ decreases from 10.709 to 8.707 up to the level 4 as shown figure 12 .

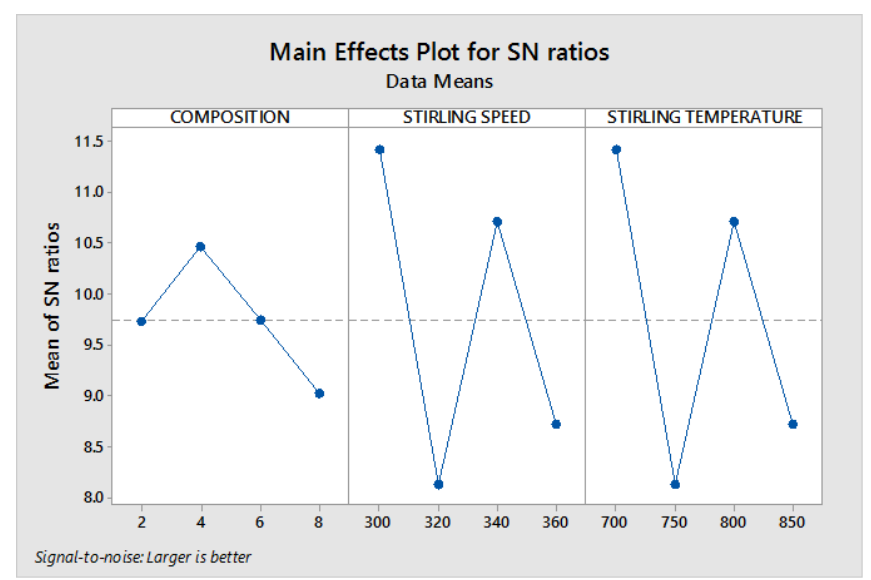

Figure 12: Main Effects plot for $\mathrm{S} / \mathrm{N}$ ratios of Ductility

\section{Effect of stirring temperature}

If the stirring temperature increases from $700^{\circ} \mathrm{C}$ to $750^{\circ} \mathrm{C}$, the mean $\mathrm{S} / \mathrm{N}$ ratio decreases from 11.428 to 8.115 up to level 2. Again the stirring temperature increases from $800^{\circ} \mathrm{C}$ to $850{ }^{\circ} \mathrm{C}$ thus $\mathrm{S} / \mathrm{N}$ decreases from 10.709 to 8.707 up to the level 4 as shown figure 12 .

\section{CONCLUSIONS}

Component hybrid Metal matrix composite (using AA-2014 as matrix, Boron carbide and Short E-glass as reinforcement) was possible by Stir Casting Method. The specimens prepared were subjected to tensile and hardness testing and the effect of reinforcement on the strength of the alloy were studied. Based on the study conducted on the Boron carbide, E-glass containing AA2014 composite material, the following conclusions can be made.

$>$ Using stir casting technique uniform distribution of reinforcement material can be obtained.

$>$ If the percentage of boron carbide and short E-glass fiber increases gradually the hardness of the hybrid composite material increases from 76.3 BHN TO 223.9 BHN.

$>$ Ductility of developed material decreases considerably as the hardness has increased significantly.

$>$ The signal-to-ratio show the effect of each process parameter at each level on the, hardness and ductility of the hybrid composite material.

\section{REFERENCES}

[1]. Feng YC, Geng L Fabrication and characteristic of Al-based hybrid composite reinforced with tungsten oxide particle and aluminum borate whisker by squeeze casting. Materials \& Design 2008;29: 2023-6.

[2]. BhargaviRebba, Studies on Mechanical Properties of 2024 Al - B4c Composites. Advanced Materials Manufacturing \& Characterization Vol 4 Issue 1 (2014).

[3]. Toptan F, Kilicarslan A, Cigdem M, Kerti 1. Processing and microstructural characterization of A1070 and AA6063 matrix B4C reinforced composites. Material Design 2010; 31; S87-91.

[4]. Zhang H, Chenb MW Rameshc KT, Yed J, Schoenung JM, Chin ESC (2006) Tensile behavior and dynamic failure of aluminum 6061 .

[5]. Raja T.1 and Effects on Microstructure and Hardness of Al-B4C Metal Matrix Composite Fabricated through Powder Metallurgy,Global Science Research Journals.pp. 001-005, March, 2014.

[6]. Author. K. Kaw "Mechanics of composite materials" Second Edition by Taylor and Francis, (2009), pp 0159. 